\title{
The Inheritance of High Density Lipoprotein Deficiency (Tangier Disease) *
}

\author{
Donald S. Fredrickson with the technical assistance of Oscar Young, \\ Tatsuji Shiratori, and Nanci Briggs
}

(From the National Heart Institute, Bethesda, Md.)

A familial syndrome consisting of complete or nearly complete absence of plasma high density lipoprotein (HDL) associated with storage of cholesterol esters in reticuloendothelial tissues has been previously reported $(1,2)$. It has been given the name Tangier disease after the community of origin of the first two cases. Its prominent clinical features include hypocholesterolemia, tonsils of unusual size and coloration, and, sometimes, hepatosplenomegaly and lymphadenopathy.

Three pairs of sibs with the full-blown syndrome have been discovered in three different kindreds $(1,3,4)$. The observation of low HDL concentrations in parents of the first sibship (1) has led to extensive study of the distribution of HDL concentrations in members of the first two kindreds. The results of this genetic survey are the subject of this report.

\section{Subjects and Methods}

Patients. Two kindreds each with a pair of sibs with Tangier disease formed the basis of this study. The propositi from kindred T (VII-2,-3, Table I) were from the island community of Tangier, Virginia, and have previously been reported in some detail $(1,2)$. Those from kindred $M$ (III-3,-4, Table II) have been only mentioned previously (3). They have been examined by the author, but have not been available for intensive inpatient study. In both kindreds, the diagnosis was established by the finding of almost complete absence of HDL by ultracentrifugal and immunoelectrophoretic analyses. The tonsils of M-III-4 also contained the histological changes and a 90-fold increase in cholesterol ester content previously described as typical of the disease (1).

Relatives. $T$ kindred. Blood samples were obtained from 127 subjects related to or from the same community as the Tangier Island propositi. All but one (IV-25, Figure 3 ) were born on the island, and eight had been living elsewhere for 1 or more years. These subjects were further subdivided into two groups: 1)

\footnotetext{
* Submitted for publication June 24, 1963; accepted Oc-
} tober $10,1963$. close relatives, including parents, grandparents, greatgrandparents, and the sibs and offspring of these and 2) the remainder, termed "distant" relatives, including 90 subjects. Many of these subjects were originally selected to serve as unrelated community controls. As pedigree information was gradually assembled, however, only 17 could not be proved to have at least one relative common to the $T$ propositi.

Tangier Island was settled in the 17th century and has had a stable population of about 900 for many generations. The original settlers were Anglo-Saxon, and all of the names of subjects studied suggest origin from the British Isles. There are no written records on the island from which comprehensive pedigree information could be obtained. Data were compiled from questionnaires on each subject and were collated and checked by repeated interviews with several of the island's older inhabitants.

$M$ kindred. In addition to the propositi, eight close relatives of the $M$ kindred were sampled. Most of the members of this kindred were from a community in western Missouri. The propositi and sibs (III 1-4, Table II) were born there; the father was born in Iowa and the mother in Pennsylvania. The paternal grandparents were both born in Missouri, and both sets of their parents were born in the southeastern part of the United States of Anglo-Saxon parents. The maternal grandparents were both born in Czechoslovakia as were their parents before them. There is no appearance of names common to the Tangier population in this pedigree and no traceable connection between it and the $\mathrm{T}$ kindred.

In neither of the affected populations was it possible to control the time of sampling with relationship to food intake. About $90 \%$ had eaten within 8 hours before sampling.

Controls. Plasma samples from 277 subjects were analyzed to serve as controls. These subjects ranged from 1 to 89 years and represented mainly NIH employees and "normal" volunteer patients, the majority having lived for some time in the Washington-Baltimore area. Most of the children 16 years and under were patients with acyanotic heart disease, well nourished and without congestive heart failure. Of subjects over 65 the majority of males were patients at the Baltimore City Hospital and the females apparently healthy residents of a home for the aged. All subjects were ambulatory, had no known family history of hyperlipidemia, and were not receiving treatment for diabetes or thyroid dys- 
TABLE I

Close relatives in the $T$ kindred*

\begin{tabular}{|c|c|c|c|c|c|c|c|c|c|}
\hline \multirow[b]{2}{*}{ No. } & \multirow[b]{2}{*}{ Sex } & \multirow[b]{2}{*}{ Age } & \multirow{2}{*}{$\begin{array}{l}\text { Fasting } \\
\text { or non- } \\
\text { fasting }\end{array}$} & \multicolumn{4}{|c|}{ Plasma } & \multicolumn{2}{|c|}{$\mathrm{D}>1.063$} \\
\hline & & & & TC & $\mathrm{FC}$ & $\mathrm{PL}$ & TG & $\mathrm{TC}$ & PL \\
\hline & & years & & \multicolumn{4}{|c|}{$m g / 100 \mathrm{ml}$} & & \\
\hline III-16 & $\mathbf{M}$ & 86 & NF & 215 & 62 & 305 & 174 & 41 & 127 \\
\hline III-17 & $\mathrm{F}$ & 77 & NF & 202 & 56 & 253 & 190 & 32 & 84 \\
\hline IV -22 & $\mathrm{~F}$ & 69 & $\mathrm{NF}$ & 165 & 33 & 246 & 164 & 32 & 107 \\
\hline IV-24 & $F$ & 68 & $\mathrm{NF}$ & 235 & 51 & 258 & 140 & 38 & 111 \\
\hline IV -27 & $F$ & 51 & $F$ & 264 & 70 & 275 & 79 & 60 & 121 \\
\hline IV-28 & $\mathbf{M}$ & 50 & $\mathrm{NF}$ & 213 & 60 & 286 & 234 & 49 & 118 \\
\hline IV -29 & $\mathrm{~F}$ & 48 & NF & 234 & 79 & 361 & 589 & 25 & 111 \\
\hline IV -30 & $\mathrm{~F}$ & 47 & $\mathrm{NF}$ & 272 & 66 & 288 & 88 & 49 & 122 \\
\hline IV-31 & M & 45 & $\mathrm{NF}$ & 203 & 57 & 291 & 537 & 28 & 108 \\
\hline IV -32 & $\mathbf{M}$ & 44 & $\mathrm{NF}$ & 299 & 95 & 472 & 1,215 & 28 & 125 \\
\hline IV-35 & $\mathbf{M}$ & 41 & NF & 239 & 70 & 309 & 406 & 30 & 98 \\
\hline IV-36 & $\mathrm{M}$ & 40 & $\mathrm{NF}$ & 253 & 73 & 330 & 487 & 26 & 99 \\
\hline IV-40 & $\mathbf{M}$ & 74 & $\mathrm{NF}$ & 254 & 77 & 326 & 341 & 40 & 105 \\
\hline V-14 & $\mathrm{F}$ & 61 & NF & 187 & 50 & 238 & 224 & 36 & 107 \\
\hline V-15 & $\mathbf{M}$ & 57 & $F$ & 132 & 32 & 175 & 40 & 32 & 91 \\
\hline V-18 & M & 49 & $\mathrm{NF}$ & 221 & 57 & 267 & 271 & 38 & 114 \\
\hline$V-19$ & M & 40 & NF & 184 & 46 & 228 & 138 & 25 & 91 \\
\hline$V-20$ & $F$ & 33 & NF & 129 & 30 & 186 & 50 & 41 & 107 \\
\hline$V-27$ & $\mathrm{~F}$ & 53 & $\mathrm{~F}$ & 214 & 58 & 239 & 170 & 30 & 89 \\
\hline $\mathrm{V}-28$ & $\mathrm{~F}$ & 50 & $\mathbf{F}$ & 246 & 60 & 290 & 101 & 37 & 102 \\
\hline$V-32$ & M & 58 & $\mathrm{NF}$ & 185 & 47 & 243 & 315 & 20 & 70 \\
\hline V-34 & $\mathbf{M}$ & 52 & $\mathrm{NF}$ & 203 & 51 & 282 & 155 & 18 & 78 \\
\hline V-35 & $\mathrm{F}$ & 50 & $\mathrm{~F}$ & 204 & 55 & 251 & 190 & 21 & 77 \\
\hline V-36 & $\mathrm{F}$ & 48 & NF & 174 & 37 & 205 & 218 & 21 & 73 \\
\hline$V-37$ & M & 36 & $\mathrm{~F}$ & 244 & 62 & 273 & 54 & 44 & 109 \\
\hline V-38 & $\mathbf{M}$ & 35 & NF & 210 & 53 & 244 & 235 & 31 & 103 \\
\hline VI-8 & M & 32 & $\mathrm{NF}$ & 165 & 38 & 256 & 484 & 15 & 76 \\
\hline VI-9 & $\mathrm{F}$ & 25 & NF & 142 & 36 & 223 & 359 & 34 & 99 \\
\hline VI-11 & $\mathbf{M}$ & 34 & NF & 157 & 41 & 218 & 153 & 21 & 77 \\
\hline VI-12 & $\mathrm{F}$ & 33 & NF & 185 & 48 & 239 & 224 & 31 & 95 \\
\hline Vl-13 & M & 32 & NF & 213 & 57 & 268 & 168 & 32 & 98 \\
\hline VI-17 & $\mathbf{M}$ & 28 & NF & 144 & 32 & 233 & 538 & 20 & 80 \\
\hline VI-18 & $F$ & 25 & $\mathrm{~F}$ & 197 & 42 & 248 & 115 & 28 & 82 \\
\hline VI-19 & M & 21 & $\mathrm{~F}$ & 169 & 35 & 243 & 104 & 49 & 136 \\
\hline VI-20 & $\mathrm{F}$ & 18 & $\mathrm{NF}$ & 144 & 33 & 203 & 82 & 41 & 113 \\
\hline VI-21 & $\mathrm{F}$ & 15 & $\mathrm{NF}$ & 152 & 37 & 225 & 362 & 30 & 99 \\
\hline VI-22 & $F$ & 11 & NF & 147 & 33 & 197 & 177 & 29 & 99 \\
\hline V1I-2 & $\mathrm{F}$ & 7 & $\mathrm{~F}$ & 59 & 17 & 128 & 310 & 1 & 19 \\
\hline VII-3 & M & 6 & $F$ & 54 & 19 & 124 & 268 & 1 & 17 \\
\hline
\end{tabular}

${ }^{*} \mathrm{TC}=$ total cholesterol, $\mathrm{FC}=$ free cholesterol, $\mathrm{PL}=$ phospholipids, $\mathrm{TG}=$ triglycerides, $\mathrm{D}=$ density, $\mathrm{F}=$ sample obtained af ter an overnight fast, $\mathrm{NF}=$ sample obtained 1 to 8 hours af ter last meal.

function. They were not otherwise screened. Lipoprotein analyses on 43 normal control subjects, ages 20 to 29 , previously made in this laboratory by the same techniques by Havel, Eder, and Bragdon (5, their Table II) were found entirely comparable to those obtained subsequently in the same age group. These earlier analyses were therefore added to the compilations, bringing the total number of control subjects to 176 males and 144 females. Of these subjects, 251 (78\%) were sampled after an overnight fast.

Blood samples. Twenty-five $\mathrm{ml}$ of antecubital vein blood was collected in heparin $(0.02 \mathrm{mg}$ per $\mathrm{ml}$ blood) and centrifuged at room temperature. The plasma was then kept at $2^{\circ} \mathrm{C}$ for periods of 1 to 30 days until fractionated in the ultracentrifuge. Blood grouping was also performed on all samples from the $\mathrm{T}$ kindred. All samples were coded, and identity of the donor was unknown to the technicians performing the analyses.
Lipid and lipoprotein determinations. Plasma was separated into two fractions of density greater and less than 1.063 by the Spinco model $\mathrm{L}$ preparative ultracentrifuge according to the method of Havel and associates (5). The density of $5 \mathrm{ml}$ of plasma was changed to 1.063 by adding a solution of $\mathrm{NaCl}$ and $\mathrm{KBr}$ of $\mathrm{D} 1.35$ (5). The plasma was then centrifuged at $100,000 \times g$ for 16 hours at $15^{\circ} \mathrm{C}$ in a 40.3 rotor. The tubes were sliced in the clear zone approximately $2.4 \mathrm{~cm}$ from the top, and the infranatant solution ( $D>1.063$ ) was made to $5 \mathrm{ml}$ with isotonic saline. Two-ml samples were directly extracted into $48 \mathrm{ml}$ of chloroform: methanol 2:1 (6). Cholesterol (7) and phospholipid (8) were determined on samples of the chloroform extract. In some samples the cholesterol and phospholipid of the supernatant lipoproteins of $\mathrm{D}<1.063$ were similarly determined.

Free and total cholesterol, phospholipid, and triglyceride 
TABLE II

Members of the $M$ kindred*

\begin{tabular}{|c|c|c|c|c|c|c|c|c|c|}
\hline \multirow[b]{2}{*}{ No. } & \multirow{2}{*}{\multicolumn{2}{|c|}{ Sex Age }} & \multirow{2}{*}{$\begin{array}{l}\text { Fasting } \\
\text { or non- } \\
\text { fasting }\end{array}$} & \multicolumn{4}{|c|}{ Plasma } & \multicolumn{2}{|c|}{$\mathrm{D}>1.063$} \\
\hline & & & & $\overline{\mathrm{TC}}$ & FC & PL & $\overline{\mathrm{TG}}$ & TC & $\overline{P L}$ \\
\hline \multicolumn{4}{|c|}{ years } & \multicolumn{6}{|c|}{$\mathrm{mg} / 100 \mathrm{ml}$} \\
\hline I-1 & $\mathbf{M}$ & 71 & F & 237 & 39 & 270 & 179 & 17 & 71 \\
\hline I-2 & F & 71 & F & 196 & 43 & 340 & 138 & 81 & 172 \\
\hline I-3 & $\mathbf{M}$ & 80 & F & 199 & 35 & 280 & 59 & 31 & 115 \\
\hline I-4 & F & 71 & F & 240 & 48 & 241 & 109 & 39 & 83 \\
\hline II-1 & $\mathbf{M}$ & 49 & $\mathrm{NF}$ & 210 & 37 & 247 & 176 & 27 & 87 \\
\hline II-2 & F & 45 & $\mathrm{NF}$ & 198 & 27 & 228 & 83 & 27 & 100 \\
\hline III-1 & M & 19 & $\mathrm{NF}$ & 146 & 16 & 225 & 106 & 46 & 129 \\
\hline III-2 & $\mathbf{M}$ & 17 & $\mathrm{NF}$ & & & & & 31 & 93 \\
\hline III-3 & $\mathrm{F}$ & 12 & F & 76 & 29 & 111 & 115 & 0 & 28 \\
\hline III-4 & F & 8 & $\mathrm{~F}$ & 117 & 33 & 136 & 224 & 0 & 21 \\
\hline
\end{tabular}

* Abbreviations as in Table I.

(9) were also determined on a plasma sample. All lipid concentrations were calculated as milligrams per $100 \mathrm{ml}$ of starting plasma.

Definition of $H D L$. The single fractionation of piasma at D 1.063 was chosen to reduce the number of manipulations and thus increase the accuracy of the more than 400 analyses required. Of the lipids in the ultracentrifugal isolate of $\mathrm{D}>1.063$, only cholesterol and phospholipid are present in accurately measurable quantities. The cholesterol is practically all confined to the density band 1.063 to 1.21 in which lies the HDL or $\alpha_{1}$-lipoprotein. An appreciable fraction of the phospholipid isolated at $\mathrm{D}>1.063$ is associated with proteins sedimenting at D 1.21 (5). Since the amounts of this "non-HDL" phospholipid are variable, only the cholesterol of $\mathrm{D}>1.063$ was used to define HDL concentrations for the purposes of this study.

Standardization and reproducibility. Sampling and analyses extended over a 24-month period, but were so arranged that lipoprotein measurements in control and affected populations were made concurrently throughout the entire period. The stability of analytical conditions was checked by standards fractionated in each rotor run. These standards of pooled citrated human plasma were frozen in samples and thawed once just before centri-

TABLE III

Reproducibility of recovery of $D>1.063$ lipids from two samples of frozen pooled human plasma

\begin{tabular}{|c|c|c|c|}
\hline \multirow[b]{2}{*}{ Pool* } & \multirow{2}{*}{$\begin{array}{l}\text { No. of } \\
\text { consec- } \\
\text { utive } \\
\text { deter- } \\
\text { mina- } \\
\text { tions }\end{array}$} & \multicolumn{2}{|c|}{$\mathrm{D}>1.063$} \\
\hline & & Cholesterol† & Phospholipid $\dagger$ \\
\hline & & \multicolumn{2}{|c|}{$\mathrm{mg} / 100 \mathrm{ml}$} \\
\hline $\begin{array}{l}\mathrm{A} \\
\mathrm{D}\end{array}$ & $\begin{array}{r}9 \\
15\end{array}$ & $\begin{array}{l}58.6 \pm 2.7 \\
53.6 \pm 6.0\end{array}$ & $\begin{array}{l}128.5 \pm 6.4 \\
129.6 \pm 7.4\end{array}$ \\
\hline
\end{tabular}

* The lipid content of plasma pool A was 174, 242, and $34 \mathrm{mg} / 100 \mathrm{ml}$ of cholesterol, phospholipid, and triglyceride, respectively; that of pool D, 176, 238, and 51.

$\dagger$ Mean \pm standard deviation. fugation. Each was used for a 4- to 6-month period during which the analyses of cholesterol and phospholipid in the $\mathrm{D}>1.063$ fraction were quite reproducible, the standard deviations averaging less than $10 \%$ of the mean ( $\mathrm{Ta}$ ble III). The sum of cholesterol in the infranatant and supernatant fractions after ultracentrifugation of standard pool "D" at D 1.063 was $94 \pm 5 \%$ (mean and standard deviation of 14 determinations) of that in the native plasma.

Repeated HDL determinations on 10 members of the Tangier population made over periods up to 23 months apart are shown in Table IV. The variation in most of the subjects lay within the analytical error with exception of the three with lowest mean values. Of these, VI-8 and VI-18 were the parents of the propositi, and possibly greater variation in such low HDL levels could be a feature of a phenotype described in the Results.

\section{Results}

\section{HDL concentrations in controls}

Effect of age. In Table $\mathrm{V}$ are presented the mean and variation in HDL concentrations obtained in each sex for three different age groups

TABLE IV

Variation of high density lipoprotein (HDL) cholesterol in individual members of the Tangier population

\begin{tabular}{|c|c|c|}
\hline Subject* & $\begin{array}{l}\text { Date of deter- } \\
\text { mination }\end{array}$ & $\begin{array}{c}\text { HDL } \\
\text { cholesterol }\end{array}$ \\
\hline \multirow{3}{*}{ IV-15 } & month year & $\mathrm{mg} / 100 \mathrm{ml}$ \\
\hline & $6 \quad 61$ & 45 \\
\hline & 562 & 46 \\
\hline \multirow[t]{2}{*}{$V-3$} & $6 \quad 61$ & 29 \\
\hline & 1161 & 33 \\
\hline \multirow[t]{2}{*}{$\mathrm{V}-20$} & 661 & 41 \\
\hline & 562 & 41 \\
\hline \multirow[t]{2}{*}{$V-48$} & $6 \quad 61$ & 29 \\
\hline & 1161 & 33 \\
\hline \multirow[t]{3}{*}{ VI-8 } & $6 \quad 61$ & 21 \\
\hline & 11 & 10 \\
\hline & 562 & 13 \\
\hline \multirow[t]{2}{*}{ VI-12 } & $6 \quad 61$ & 25 \\
\hline & 1161 & 17 \\
\hline \multirow[t]{7}{*}{ VI-18 } & 261 & 21 \\
\hline & 461 & 33 \\
\hline & $6 \quad 61$ & 34 \\
\hline & 861 & 18 \\
\hline & 1161 & 32 \\
\hline & 562 & 33 \\
\hline & 163 & 26 \\
\hline \multirow[t]{2}{*}{ VI-20 } & 661 & 42 \\
\hline & 562 & 39 \\
\hline \multirow[t]{5}{*}{ VII-2 } & 1260 & 2 \\
\hline & 261 & $<1$ \\
\hline & 661 & 2 \\
\hline & 1161 & 1 \\
\hline & 562 & $<1$ \\
\hline \multirow[t]{3}{*}{ VII-3 } & 1260 & $<1$ \\
\hline & $6 \quad 61$ & 2 \\
\hline & 562 & $<1$ \\
\hline
\end{tabular}

* Code designations as in Table I and Figure 3. 


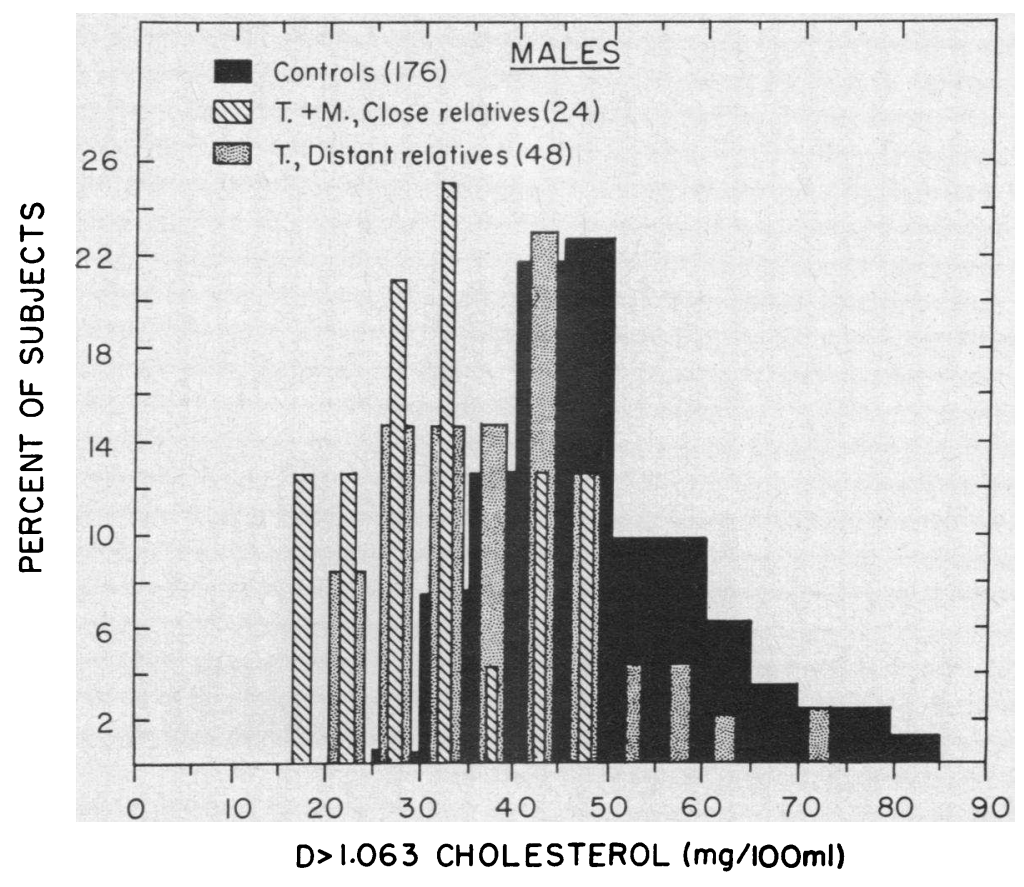

Fig. 1. Distribution OF High DENSity Lipoprotein ChOlEsterol iN male members of the control and affected populations. The definition of close and "distant" relatives is explained in the text.

among the controls. The mean concentration in each age group was significantly lower in males $(p<0.05)$. Within each sex the differences between the means of the several age groups were not statistically significant, with the exception of that between females of ages 1 to 25 and 26 to 51 years $(\mathrm{p}<0.05)$.

The range of HDL cholesterol values was in good agreement with those obtained by others using the same (5) or different methods of isolation (10-13). Such previous studies, and several others using the analytical ultracentrifuge (14, 15), have all consistently demonstrated higher HDL concentrations in the female.

Prior reports, dealing with a smaller age range, have interpreted any effects of age on HDL in differing ways. In males, the largest single study by Gofman and associates (15) showed a fall in concentrations from ages 18 to about 30 , with a small rise thereafter. Carlson (13) found in Swedish males that HDL increased about $20 \%$ from ages 18 to 26 to ages 56 to 65 . Others have reported a slight rise (10) or no change (11, 14) with age. In females, a rise (14) or over-all modest decrease $(10,11,15)$ with age has been reported.

The mean ages in the males and females in the combined affected populations were 39.6 and 40.3 years for males and females, respectively. For subsequent comparisons the data for each sex were pooled, the likelihood being small that any small age-related changes in HDL would significantly bias the results.

TABLE $V$

High density lipoprotein (HDL) cholesterol concentrations in control subjects

\begin{tabular}{|c|c|c|c|c|}
\hline Sex & $\begin{array}{l}\text { No. of } \\
\text { subjects }\end{array}$ & Range & Age* & $\begin{array}{c}\mathrm{D}>1.063 \\
\text { cholesterol* }\end{array}$ \\
\hline \multirow{5}{*}{$\mathbf{M}$} & & & years & $\mathrm{mg} / 100 \mathrm{ml}$ \\
\hline & 176 (total) & $1-84$ & $37.9 \pm 8.2$ & $48.0 \pm 11.2$ \\
\hline & 28 & $1-25$ & $12.5 \pm 8.2$ & $47.5 \pm 10.4$ \\
\hline & 115 & $26-50$ & $37.6 \pm 7.9$ & $47.8 \pm 10.6$ \\
\hline & 33 & $51-84$ & $60.5 \pm 9.4$ & $49.2 \pm 14.1$ \\
\hline \multirow[t]{4}{*}{$\mathbf{F}$} & 144 (total) & $1-89$ & $43.5 \pm 9.3$ & $56.7 \pm 13.7$ \\
\hline & 36 & $1-25$ & $16.1 \pm 8.1$ & $53.8 \pm 13.7$ \\
\hline & 48 & $26-50$ & $37.7 \pm 7.7$ & $60.1 \pm 12.5$ \\
\hline & 60 & $51-89$ & $64.6 \pm 11.0$ & $55.7 \pm 14.8$ \\
\hline
\end{tabular}

* Mean \pm standard deviation. 


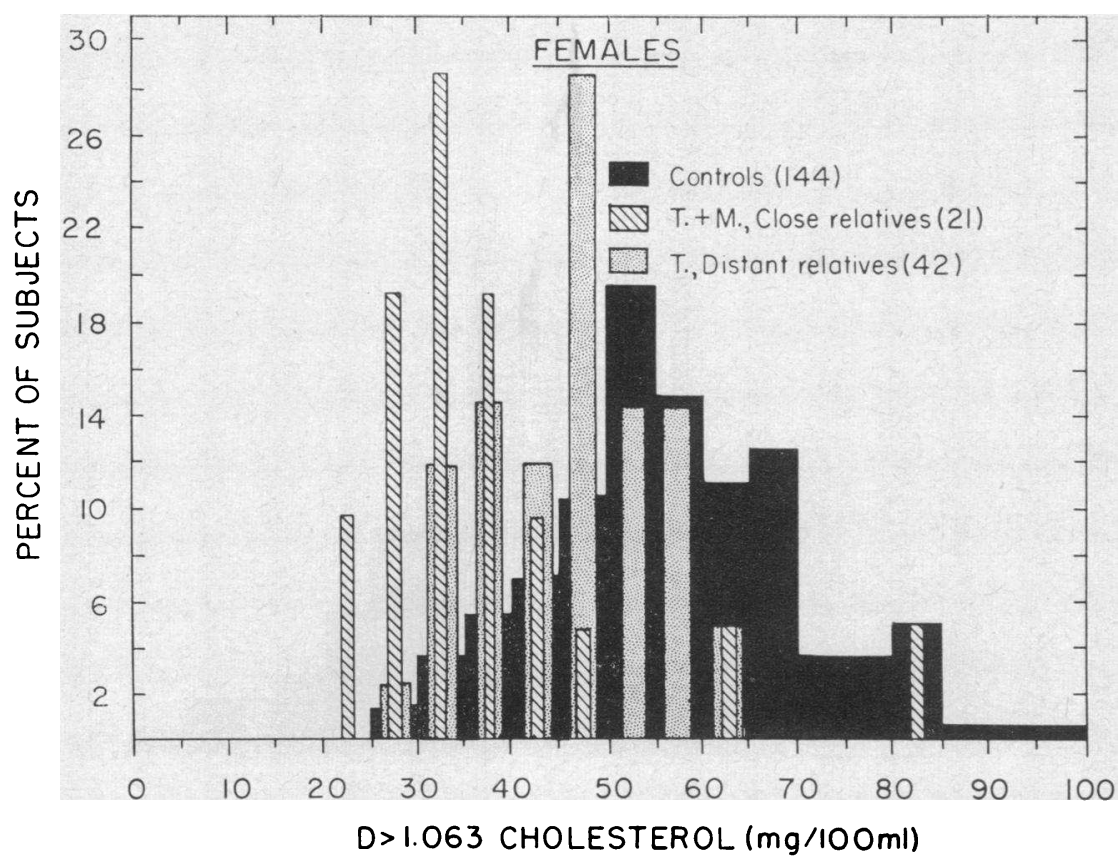

Fig. 2. Distribution of high Density Lipoprotein ChOlesterol in FEMALE MEMBERS OF THE CONTROL AND AFFECTED POPULATIONS.

Frequency distribution. The HDL concentrations in each sex are shown in Figures 1 and 2. They were not normally distributed in either males $\left(\mathrm{p}<0.001 ; \chi^{2}=36.0 ;\right.$ no. $\left.=8\right)$ or females $(\mathrm{p}<$ $0.05 ; \chi^{2}=17.69 ;$ no. $=9$ ).

Nutritional state. The mean HDL cholesterol concentrations in 140 fasting and 36 nonfasting males were 48.2 and $46.1 \mathrm{mg}$ per $100 \mathrm{ml}$, respectively. In 111 fasting and 33 nonfasting females the respective means were 57.6 and $53.6 \mathrm{mg}$ per $100 \mathrm{ml}$. These differences were not statistically significant. It has been previous'y shown by Havel (16) that food ingestion for 4 to 8 hours before blood sampling will produce either no change or a 5 to $10 \%$ increase in HDL cholesterol in normal subjects. Any bias due to differences in the timing of samples in the control and affected populations can therefore be expected to be small and in the direction of increasing the HDL in the affected populations.

\section{$H D L$ concentrations in affected populations}

The frequency distribution of HDL in the affected populations is illustrated alongside that of the controls in Figures 1 and 2. For purposes of analysis, the relatively few data from the $M$ kindred (Table II) were combined with the close relatives from the Tangier kindred. In both sexes the HDL distribution in the close relatives was displaced to the left, the mean concentrations lying far below those of the controls. Of the 24 male close relatives, over $70 \%$ had HDL concentrations below $33 \mathrm{mg}$ per $100 \mathrm{ml}$, compared to only $4.5 \%$ of controls. In male "distant" relatives the mean HDL was higher, but still less than that of control males. The values were widely spread, overlapping the major peaks of distribution observed in both close relatives and controls.

The HDL distribution in female close relatives (Figure 2) was likewise shifted far below that in the controls, almost $60 \%$ being below $35 \mathrm{mg}$ per $100 \mathrm{ml}$ in contrast to less than $5 \%$ of the controls. The "distant" female relatives again were shifted toward the normal range, with peaks of distribution occurring near those for close relatives and the controls.

It was not possible to prove the presence of two modes of distribution in the affected populations by the $\chi^{2}$ test, even with a variety of methods of pooling the data in addition to those shown in Figures 1 and 2. Nevertheless, it seemed very 


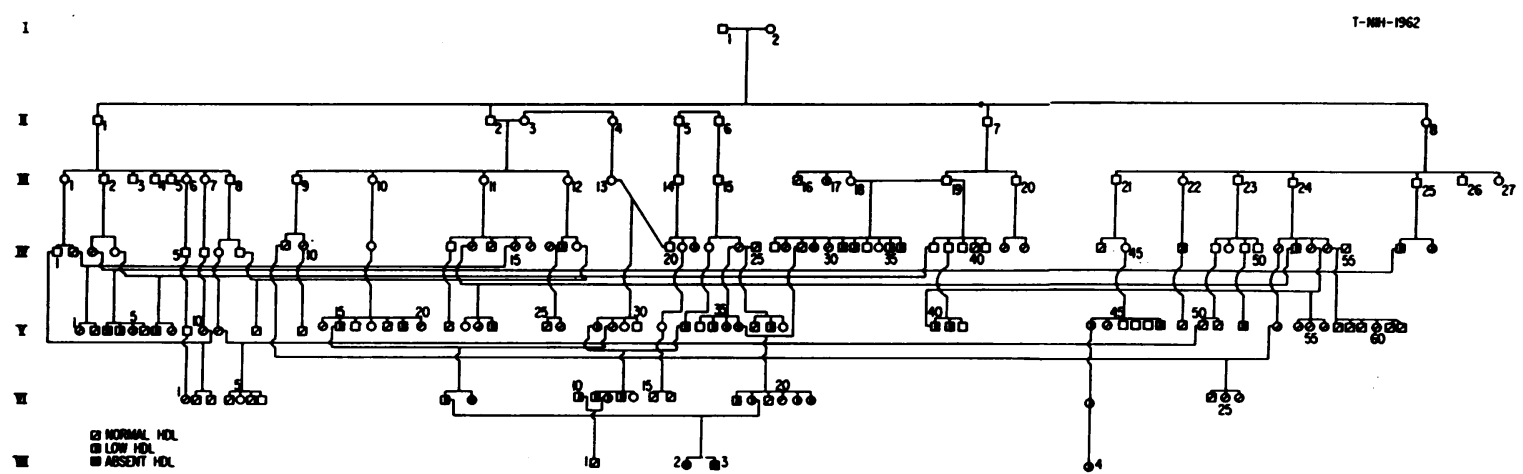

Fig. 3. The PEdigree of the TANGIER PROPOSITI SHOWING THE DistRIBUtion OF HIGH DENSITY LIPOPROTEIN concentrations among 109 close and "Distant" relatives. Details concerning the 37 close relatives from whom samples were obtained are presented in Table I.

likely that a portion of these subjects uniquely departed from normal and that the major difficulty in accurately segregating such "abnormal" HDL concentrations lay in the extreme range and skewed distribution of HDL in the control subjects. Since fiducial limits calculated for a normal distribution could not be used, values were arbitrarily selected below which HDL might be considered abnormal. The cut-off values chosen were those below which less than $5 \%$ of the controls were found, or 33 and $35 \mathrm{mg}$ per $100 \mathrm{ml}$ for males and females, respectively. Figures 1 and 2 show that these were conservatively selected, coinciding with the lower of the two maxima in the distributions of HDL in members of the affected populations.

$H D L$ distributions within pedigrees $T$ and $M$. Despite the error inherent in their definition, the distribution of such low ("abnormal") HDL values among relatives of the two sets of propositi proved extremely interesting. The pedigrees are illustrated in Figures 3 and 4 . No history of consanguinity, so prevalent in the $\mathrm{T}$ kindred, could be elicited for the $M$ kindred.

In both kindreds each parent of the propositi and one of each pair of grandparents had low HDL. This distribution and the HDL patterns observed in remaining relatives were consistent with the inheritance of Tangier disease in Mendelian terms as an autosomal recessive. This mode requires the hypothesis that major control of plasma HDL concentrations be exerted by a single pair of alleles. The genotype, AA, would be associated with normal HDL levels; the presence of a single abnormal mutant, $\mathrm{Aa}$, with "abnormally low" HDL; and the rare homozygous abnormal, aa, with lack of any significant HDL and profound tissue storage of cholesterol esters.

Phenotype in other matings. The assignment of phenotype is no doubt subject to significant error and can be validated only by the appearance of the full-blown syndrome, or homozygous abnormal, within a sibship. Some further support of this genetic hypothesis is offered by data in Table VI comparing the phenotypes, as defined by HDL concentrations, of 45 offspring from 14 matings in the affected populations. . For five matings in which both parents had normal HDL all but one of the 16 offspring were also normal. The HDL concentration in the one "heterozygous" subject (V-38, Table I) was $31 \mathrm{mg}$ per $100 \mathrm{ml}$, or $6 \%$ less than the arbitrary cut-off point. HDL in the mother (IV-28, Table I) was about $10 \%$ above the cut-off point. Although this exception is inconsistent with the proposed genetic mode, it may only indicate the error in determining genotype by HDL concentrations alone. Among the sampled offspring of five matings of one normal

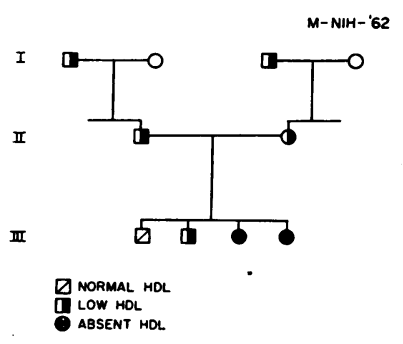

Fig. 4. Distribution OF HIGH DENSITY LIPOPROTEIN CONCENTRATIONS AMONG MEMBERS OF THE M KINDRED. Details concerning each subject are presented in Table II. 
and one abnormal subject the distribution of phenotypes was quite different, evenly divided between normal and abnormal as would be predicted. For the four matings involving two abnormal parents the results are consistent with the predicted, but the only sibships sampled completely were those containing the propositi. The number of complete sibships thus sampled is insufficient for statistically significant comparison of these data with the expected Mendelian ratios.

A true estimate of abnormal gene frequency in the Tangier population as a whole is also not possible. The sample is still relatively small and biased by an emphasis on relatives. As a rough estimate it might be reasonable to take the frequency of low HDL in "distant" relatives. In females this was 0.12 ( 5 of 42 ) and in males 0.31 (15 of 48), or an over-all frequency of about 0.2 . With random matings, the frequency of the full-blown disease should be about 1 per 100. About 200 of the island population have been examined without discovery of cases other than the two original propositi.

The frequency of the disease in the general population is undoubtedly far below the 6 per 10,000 it would be if the arbitrary cut-off points at $5 \%$ were considered true discriminants of phenotype. There were no infant deaths or stillbirths in either the $T$ or $M$ sibships. Thus no evidence is available suggesting that the presumed homozygous genotype is semilethal to help explain the rarity of the full-blown disease.

\section{Discussion}

In contrast to many studies involving familial disordering of low density lipoproteins (LDL) and particulate lipids in plasma, this appears to be the first study dealing with the genetic control of HDL. Evidence has been presented that a single pair of autosomal alleles exert major control over plasma HDL concentrations and that absence of the lipoprotein (Tangier disease) results from a double dose of an abnormal mutant at this locus.

There seems little doubt that Tangier disease is genetically determined. The presence of the disease and a similar distribution of low HDL values in the $\mathrm{M}$ kindred, remote from Tangier Island, greatly strengthen the argument for a rare mu- tant allele as the basis of the disease. Very recently two other cases in siblings from an unrelated kindred in a Kentucky community (4) have been discovered. These findings make it practically impossible that some combination of environmental factors alone could account for so unusual a familial pattern of HDL concentrations in Tangier disease.

The available data fail to prove that multiple genetic factors and possibly environmental forces are not important, especially in producing both the great spread in normal subjects and in expression of the "carrier" state for the disease. It was not possible to prove two distinct modes of distribution of HDL concentrations in the affected populations. The HDL values in the "distant" relatives of the Tangier kindred also appeared to be shifted slightly lower than the controls (Figures 1 and 2), as though possibly depressed by some additional influences. Because so many of the Tangier subjects have distant relationship to the $T$ propositi, it is unlikely that a large, well-validated sample could be obtained to serve as an ideal control of environmental forces on the island. A number of HDL values in the "normal" range were obtained on the island, however, and their distribution also followed familial patterns (Figure 3).

The genetically determined defect in Tangier disease remains to be discovered. A specific block in HDL formation is the most attractive hypothesis but by no means the sole possibility. Altered concentrations of lipoproteins whose protein moiety is different from HDL have been observed in the disease. In the $\mathrm{T}$ propositi and the

TABLE VI

Phenotypes in offspring of matings in which the phenotype of both parents was defined

\begin{tabular}{|c|c|c|c|c|c|}
\hline \multirow[t]{2}{*}{$\begin{array}{c}\text { Matings } \\
\text { HDL* }^{*}\end{array}$} & \multicolumn{3}{|c|}{$\begin{array}{l}\text { Offspring } \\
\text { HDL }\end{array}$} & \multirow[b]{2}{*}{$\begin{array}{l}\text { Low } \\
\text { (Aa) }\end{array}$} & \multirow[b]{2}{*}{$\underset{(a a)}{\text { Absent }}$} \\
\hline & No. & $\begin{array}{c}\text { Total } \\
\text { no. }\end{array}$ & $\begin{array}{l}\text { Normal } \\
(\text { AA) }\end{array}$ & & \\
\hline$\underset{(A A)}{\text { Normal }} \times \underset{(\text { AA })}{\text { Normal }}$ & 5 & 16 & 15 & 1 & o \\
\hline$\underset{(A A)}{\text { Normal }} \times$ Low & 5 & 19 & 9 & 10 & 0 \\
\hline$\underset{(\mathbf{A a}) \quad \text { (Aa) }}{\text { Low }} \times$ & 4 & 10 & 2 & 4 & $4 \dagger$ \\
\hline
\end{tabular}

* High density lipoprotein.

† The four propositi from the $T$ and $M$ kindreds. Only this mating was included from the $M$ kindred. All others are from the Tangier population and also appear in Figure 3. 
two most recently discovered cases (4) the plasma concentrations of the LDL fraction of D 1.019 to 1.063 have been significantly decreased. ${ }^{1}$ There was associated elevation of the LDL fraction of $\mathrm{D}<1.019$. A second interesting observation is that made so far in six patients with Gaucher's disease, a condition in which reticuloendothelial cells are actively storing lipid as is the case in Tangier disease. All of these have had a significant reduction in plasma HDL, in the absence of hyperglyceridemia. ${ }^{1}$ Thus there are remote possibilities of other familial processes acting less specifically on more than one lipoprotein in Tangier disease, perhaps involving stimulation of reticuloendothelial tissues to remove chemically normal HDL, and possibly a fraction of LDL, from the circulation.

Some rebuttal to the latter arguments is offered by findings in several Tangier "heterozygotes" who have marked depression of HDL concentrations. The mother of the T propositi (VI-18, Table I) has normal concentrations of LDL of D 1.019 to 1.063 (1). Tonsillectomy was performed on subject VI-12 (Table I). The tonsillar lipids were completely normal, and there was no histological evidence of reticuloendothelial storage of lipid. ${ }^{1}$

Final proof of the strong suggestion offered by this study that the defect in Tangier disease lies in the synthesis of the HDL protein or the subsequent assembly of the lipoprotein molecules will be of great value. There is already overwhelming chemical and metabolic evidence (17) that the protein moieties in plasma LDL and HDL are different, and a clear demonstration of different genetic control will ascertain fully that these two transport systems have evolved independently, presumably to serve different functions.

The control at a single gene locus of all lipoproteins isolated in the broad density band 1.063 to 1.21 is also of further interest in the study of the chemistry of the HDL protein. Evidence has recently been presented (18) that the proteins isolated at different densities within the entire HDL band have similar absorption spectra, amino acid composition, and rates of metabolic degradation. Scanu, Lewis, and Page (19) have also interpreted earlier work (20), as well as their own,

1 Unpublished observations. as showing that all HDL lipoproteins are antigenically similar.

There are other data attesting to some heterogeneity of HDL, however. Several subfractions isolated in the ultracentrifuge or by column chromatography have shown differences in metabolic behavior $(15,21)$ and antigenic heterogeneity (22). The HDL protein may also show evidence of dissociation into two components under certain conditions (23). None of these findings is inconsistent with the interpretation advanced by Shore (24) that the protein moiety of HDL having an average density of 1.09 might be a dimer of the protein in HDL of greater density. If this is so, then a single protein would initially be elaborated in the formation of HDL, and any heterogeneity observed in this lipoprotein system could still arise through changes in tertiary structure and lipidation of this protein. It is possible that the Tangier "heterozygote" will reveal some abnormalities in the decreased amounts of HDL which they have circulating and thus offer further insight into the mechanisms whereby the HDL protein becomes a lipoprotein and carries out its still obscure function.

\section{Summary}

Plasma concentrations of high density lipoprotein (HDL), as measured by cholesterol in the ultracentrifugal fraction of $\mathrm{D}>1.063$, have been determined in 135 subjects related to two sibships with Tangier disease. These have been compared with HDL concentrations in 320 control subjects extending over the same age range.

A large number of subjects in the affected population had HDL concentrations shifted well below the control distribution in both sexes. "Abnormally low" HDL concentrations, defined by arbitrary cut-off points, were distributed in the kindreds consistent with the following hypothesis: 1) a single pair of autosomal genes exerts major control over plasma HDL concentrations, 2) the phenotype due to a single abnormal mutant may be recognized by low HDL concentrations, and 3) the homozygous abnormal has no significant plasma HDL and the tissue storage of cholesterol esters typical of the full-blown syndrome.

The genetically determined defect in Tangier disease is not yet known. It is speculated that it 
may involve the elaboration of the characteristic HDL protein.

\section{Acknowledgments}

We gratefully acknowledge the invaluable assistance given by Paul H. Altrocchi, James R. Carter, Jr., James W. Egan, Joseph A. Falzone, Jr., Alfred I. Holtz, Katsuto Ono, Virginia T. Ono, and Charles H. Pope, Jr., in the collection of samples, by Eleanor Gundling in collation of data, and by Mrs. Nettie Crockett Pruitt and Mrs. Peggy Laird in coordination of pedigree information.

\section{Addendum}

In November 1963, it was possible to analyze another set of plasma samples from four members of the $M$ pedigree. The HDL concentrations of the propositi and father (Table II and Figure 4) were unchanged. The mother (II-2, Table II) now had normal concentrations of lipids of D $>1.063$ (cholesterol, 49, and phospholipids, $128 \mathrm{mg}$ per $100 \mathrm{ml}$ ). On an earlier occasion (3) her D $>1.063$ cholesterol had been normal but the phospholipid markedly low. Such variation is interpreted as similar to that detected in the mother of the Tangier propositi (VI-18, Table IV) and an unexplained feature of the apparent heterozygote in Tangier disease.

\section{References}

1. Fredrickson, D. S., and P. H. Altrocchi. Tangier disease (familial cholesterolosis with high-density lipoprotein deficiency) in Cerebral Sphingolipidoses. A Symposium on Tay-Sachs Disease and Allied Disorders, S. M. Aronson and B. W. Volk, Eds. New York, Academic Press, 1962, p. 343.

2. Fredrickson, D. S., P. H. Altrocchi, L. V. Avioli, D. S. Goodman, and H. C. Goodman. Tangier disease. Ann. intern. Med. 1961, 55, 1016.

3. Fredrickson, D. S., T. Shiratori, and O. M. Young. Genetic control of high-density lipoprotein concentrations in man (abstract). Circulation 1962, 26, 653.

4. Hoffman, H. N., and D. S. Fredrickson. Tangier disease: report of two new cases, including clinical features in adults. Submitted for publication.

5. Havel, R. J., H. A. Eder, and J. H. Bragdon. The distribution and chemical composition of ultracentrifugally separated lipoproteins in human serum. J. clin. Invest. 1955, 34, 1345.

6. Bragdon, J. H. Extraction of lipids from serum in Lipids and the Steroid Hormones in Clinical Medicine, F. W. Sunderman and F. W. Sunderman, Jr., Eds. Philadelphia, Lippincott, 1960, p. 6.

7. Sperry, W. M., and M. Webb. A revision of the Schoenheimer-Sperry method for cholesterol determination. J. biol. Chem. 1950, 187, 97.
8. Stewart, C. P., and E. B. Hendry. The phospholipins of blood. Biochem. J. 1935, 29, 1683.

9. Bragdon, J. H. Colorimetric determination of blood lipides. J. biol. Chem. 1951, 190, 513.

10. Russ, E. M., H. A. Eder, and D. P. Barr. Proteinlipid relationships in human plasma. I. In normal individuals. Amer. J. Med. 1951, 11, 468.

11. Nikkilä, E. Studies on the lipid-protein relationships in normal and pathological sera and the effect of heparin on serum lipoproteins. Scand. J. clin. Lab. Invest. 1953, 5, suppl. 8.

12. Jencks, W. P., M. R. Hyatt, M. R. Jetton, T. W. Mattingly, and E. L. Durrum. A study of serum lipoproteins in normal and atherosclerotic patients by paper electrophoretic techniques. J. clin. Invest. 1956, 35, 980.

13. Carlson, L. A. Serum lipids in normal men. Acta med. scand. 1960, 167, 377.

14. Lewis, L. A., and I. H. Page. Electrophoretic and ultracentrifugal analysis of serum lipoproteins of normal, nephrotic and hypertensive persons. Circulation 1953, 7, 707.

15. Gofman, J. W., O. De Lalla, F. Glazier, N. K. Freeman, F. T. Lindgren, A. V. Nichols, B. Strisower, and A. R. Tamplin. The serum lipoprotein transport system in health, metabolic disorders, atherosclerosis and coronary heart disease. Plasma (Milano) 1954, 2, 413.

16. Havel, R. J. Early effects of fat ingestion on lipids and lipoproteins of serum in man. J. clin. Invest. 1957, 36, 848.

17. Fredrickson, D. S., and R. S. Gordon, Jr. Transport of fatty acids. Physiol. Rev. 1958, 38, 585.

18. Scanu, A., and W. L. Hughes. Further characterization of the human serum D 1.063-1.21, $\alpha_{1}$-lipoprotein. J. clin. Invest. 1962, 41, 1681.

19. Scanu, A., L. A. Lewis, and I. H. Page. Studies on the antigenicity of $\beta$ - and $\alpha_{1}$-lipoproteins of human serum. J. exp. Med. 1958, 108, 185.

20. DeLalla, L., L. Levine, and R. K. Brown. Immunologic studies of human high density lipoproteins. J. exp. Med. 1957, 106, 261.

21. Carlson, L. A. Chromatographic separation of serum lipoproteins on glass powder columns. Description of the method and some application. Clin. chim. Acta 1960, 5, 528.

22. Aladjem, F., M. Lieberman, and J. W. Gofman. Immunochemical studies on human plasma lipoproteins. J. exp. Med. 1957, 105, 49.

23. Sanbar, S. S., P. Alaupovic, and R. H. Furman. Isolation and chemical composition of human plasma alpha-lipoprotein and its protein moieties (abstract). Circulation 1962, 26, 670.

24. Shore, B. C- and N-terminal amino acids of human serum lipoproteins. Arch. Biochem. 1957, 71, 1. 